\title{
QUANTITATIVE VARIATION IN SUBSEXUAL RUBUS
}

\author{
GORDON HASKELL \\ John Innes Horticultural Institution, Hertford
}

Received 14.ii.53

\section{SUBSEXUAL REPRODUCTION}

IN apomictic lines the occurrence of individuals not resembling the mother was attributed, in the early days of genetics, to mutation, as shown in the works of Lidforss and Ostenfeld. Yet segregation and recombination can follow from crossing-over when reduction is suppressed. How this situation arises with diploid parthenocarpy in plants has been explained by Darlington (1932), who later (1937) named it subsexual reproduction (table I). Gustafsson (1942) drew attention to the significance of such " auto-segregation," especially with regard to the European blackberry flora.

TABLE I

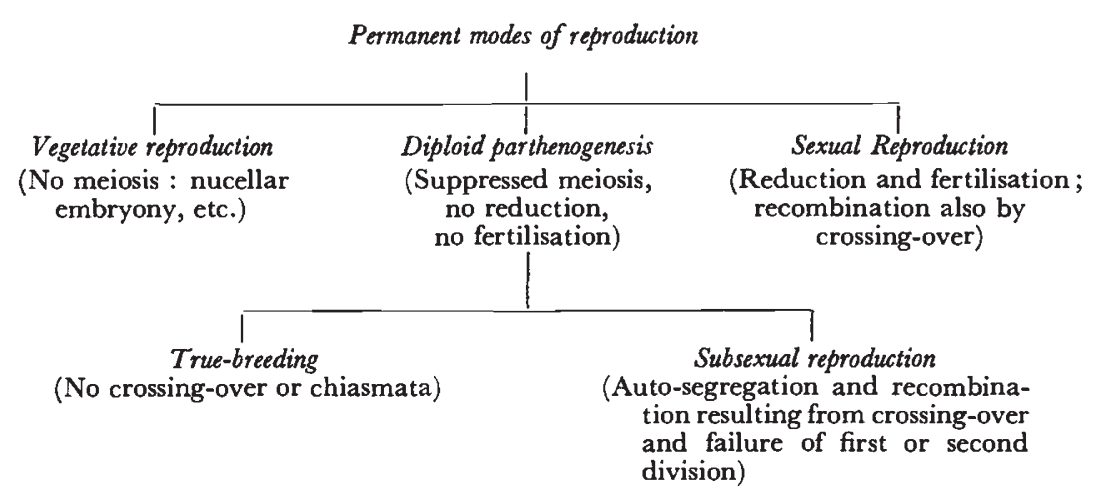

Since Lidforss in 1907 showed evidence of auto-segregation in Rubus, further study was not made until Darrow and Waldo (1933) obtained auto-segregation in parthenogenetic Rubus. In Rubus species-crosses Crane and Thomas (1939, 1940) also showed the presence of true sexual hybrids along with maternal, that is parthenogenetic, offspring which themselves varied. Gustafsson (1942) explained that this is important as a means of biotype formation in apomicts with extinct sexuality.

Previous observations of Lidforss, Ostenfeld and Gustafsson were concerned with qualitative variations. The only attempt to study quantitative variation has been that of Babcock and Stebbins (1938), who were interested in showing greater variation among sexual than among apomictic forms of Crepis and seem to have assumed that the apomicts were constant. This they did by comparison of inflorescence 
and bract sizes in apomictic and sexual strains. In the light of what I am going to show, they were studying the first example of quantitative variation with subsexual reproduction.

In all previous instances with Rubus, auto segregates were produced morphologically distinct from the mother plant. In the present study two families totalling 309 plants of Merton Early blackberry were investigated. But no plant could clearly be said to differ sharply from the rest. Only continuously varying quantitative characters were therefore available for study.

\section{MATERIAL : RUBUS NITIDIOIDES}

Rubus nitidioides Watson, is a cultivated tetraploid blackberry $(2 n=28)$, known as Merton Early, sometimes clonally propagated from stem tips but more often grown from seeds. There is little variation in these seedlings (Crane, 194I). Yet although recognising it as apomictic, Crane and Thomas (1939) observed some variation in apomictic offspring after pollination with $R$. thyrsiger $(2 n=28)$. They concluded that apomictic embryos arose by subsexual reproduction. In detailed cytological and embryological studies, Thomas (1940) found that $R$. nitidioides reproduces mainly by apospory, which does not allow for segregation, and also by the fusion of two haploid nuclei within the embryo-sac, which would allow for segregation.

The variation found by Crane and Thomas was largely quantitative. In the present biometrical analysis I have therefore attempted to present some of the features of quantitative variation in offspring of "selfed" and "sibbed" families of subsexual $R$. nitidioides, in relation to the theory of auto-segregation. Assessment is then made of the possible value of auto-segregation in plant improvement and the possibility discussed of effective selection within subsexual families.

\section{METHODS}

Seeds of a number of closely similar open-pollinated plants were collected and sown together in seed-boxes at Merton in 1945. Plants from these are Family 3I/45. Flowers of one plant (No. I) having good appearance were selfed, and their seeds sown as Family $32 / 45$. Seedlings were transferred to permanent rows at Bayfordbury in I 946 and spaced $2 \mathrm{ft}$. apart in rows. As Rubus germinates irregularly, three separate plantings of both families were made. The results of all plantings have been pooled for analysis. Plants were strung up with not more than four shoots per plant, and old branches annually cut back.

Altogether 84 seedlings of Fam. 31 and 225 of Fam. 32 were planted out. Some plants have suffered from depression, due to an unidentified disease. Quantitative measurements were taken in 1952. Prickles were counted on the two internodes of each available branch 
at $3 \mathrm{ft}$. from the ground, and mean prickle number per internode calculated. Prickle size was judged by the eye on internodes at $5 \frac{1}{2} \mathrm{ft}$. from the ground, or towards the ends of branches when these were lower. In addition, records were taken of times of first flowering, and of first fruit maturity. Qualitative characters such as prickle type, flower colour, leaflet number, and whether inflorescences were long or short, were also noted. All these were non-segregating, both families being remarkably uniform morphologically. There were no noticeable differences in fruit flavour.

\section{RESULTS}

\section{(i) Plant vigour and shooting ability}

Plants were placed in five categories for vigour, measured in April-May 1952. Growth ranged from very weak types, obviously attacked by a fungus or virus, to highly vigorous plants. The histograms in fig. I show that most plants of both populations are vigorous $(v)$.

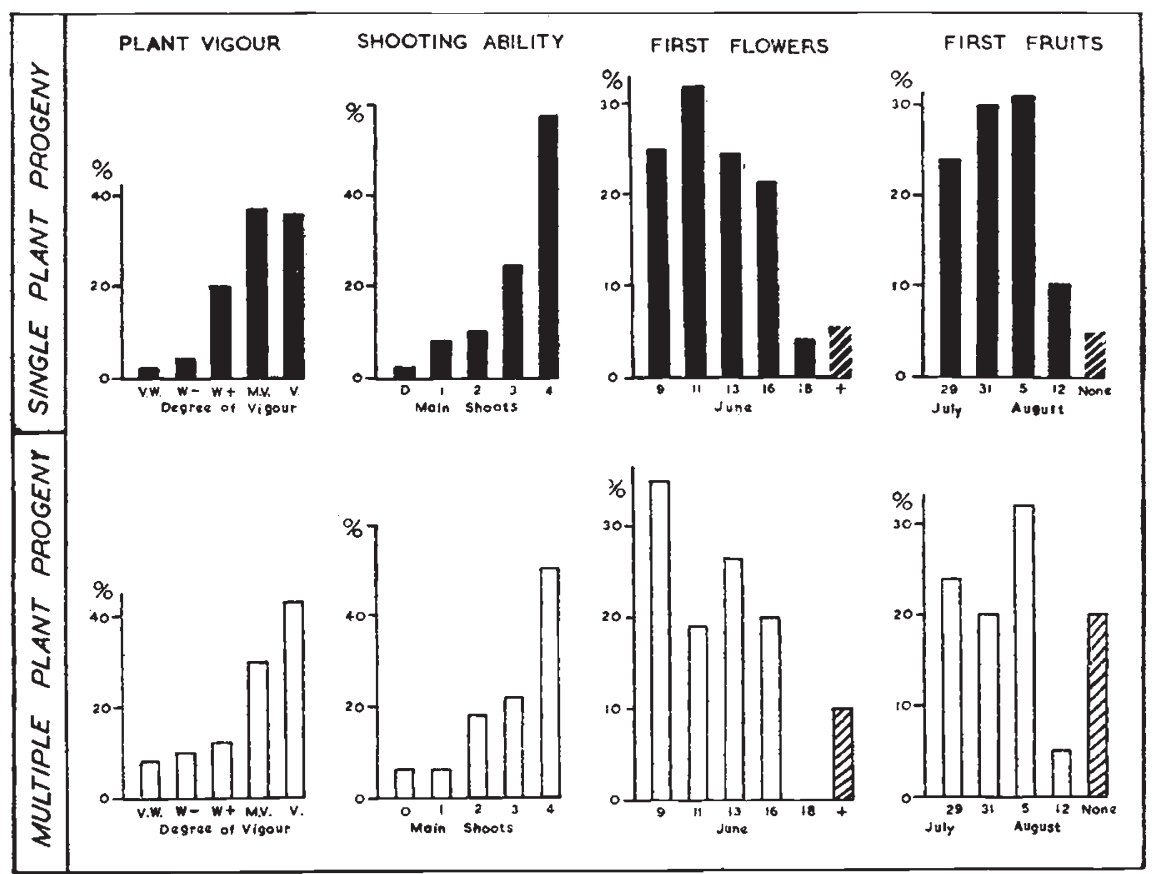

Frg. 1.-Histograms of quantitative characters in Rubus nitidioides. Offspring from several "open-pollinated" plants (Fam. 31) represented by open bars; offspring from one selected plant "self-pollinated" (Fam. 32) by black bars.

Reduced vigour of very weak (v.w.) and some of the weak (w-) ones is directly attributable to disease depression. Fam. 3 I differs slightly from Fam. 32 as it contains more plants in the extreme categories, while in Fam. $3^{2}$ there are comparatively more plants in the central part 
of the distribution range. The more extreme differences in Fam. $3^{1}$ in vigour could be due to the tails of several distributions overlapping. Fam. 3I might therefore consist of the frequency distributions of separate apomictic auto-segregating populations.

Shooting ability in spring was judged by the number of shoots tied up in autumn ready for flowering the following year. The maximum was four, if available. Fig. I shows that somewhat more plants having more shoots were produced in Fam. 32. The parent of Fam. 32 had been selected for vigour and general good plant characters; its progeny show this influence slightly. The plants were no less vigorous than those of a clonally reproduced stock. Inbreeding depression is thus not present. There is a positive correlation between shooting ability and plant vigour, not unexpected, as one is an index of the other. Hence the more vigorous seedlings are likely to produce plants with the more abundant fruiting.

\section{(ii) Prickle size and number}

Histograms for prickle sizes in both families show that slightly more plants in Fam. 32 have larger prickles. Data on very small prickles are somewhat unreliable, as disease infection reduces prickle size and frequency. There is a strong positive correlation between prickle size and plant vigour. The latter was greater in Fam. 32 than in Fam. 31, and this may account for the higher frequency of larger sized prickles in Fam. 32. All prickles were of uniform morphology.

Frequency distributions for prickle numbers are given in fig. 3 . Here it is seen that Fam. 32 has a normal frequency distribution with a sharp peak between 20 to 24 prickles per internode. Fam. 31 has a somewhat narrower range and no sharp peak, the frequency from I6 to 24 prickles per internode being the same, and with a slight increase only from 24 to 28 . It is clear from fig. 3 that Fam. 32 comprises a single segregating population, while Fam. 3 I contains a series of overlapping frequency distributions with peaks both higher and lower than 20 to 24 , as in Fam. 32.

Actual number of prickles, prickle size and plant vigour are also correlated, although average prickle number only increases by two prickles between plants of weakish habit and very vigorous ones (fig. 2). These correlations have to be borne in mind when attempting to select less prickly but vigorous plants for breeding purposes.

\section{(iii) Blossoming and fruiting}

Histograms of the frequencies of first flowering times are given in fig. I. Here it is seen that Fam. 31 contains more at the extreme periods of flowering, although the range of Fam. 32 is just as wide. Over go per cent. of both populations had flowered within nine days. Considering the effects due to pruning and other environmental factors, both populations are remarkably uniform in flowering. 


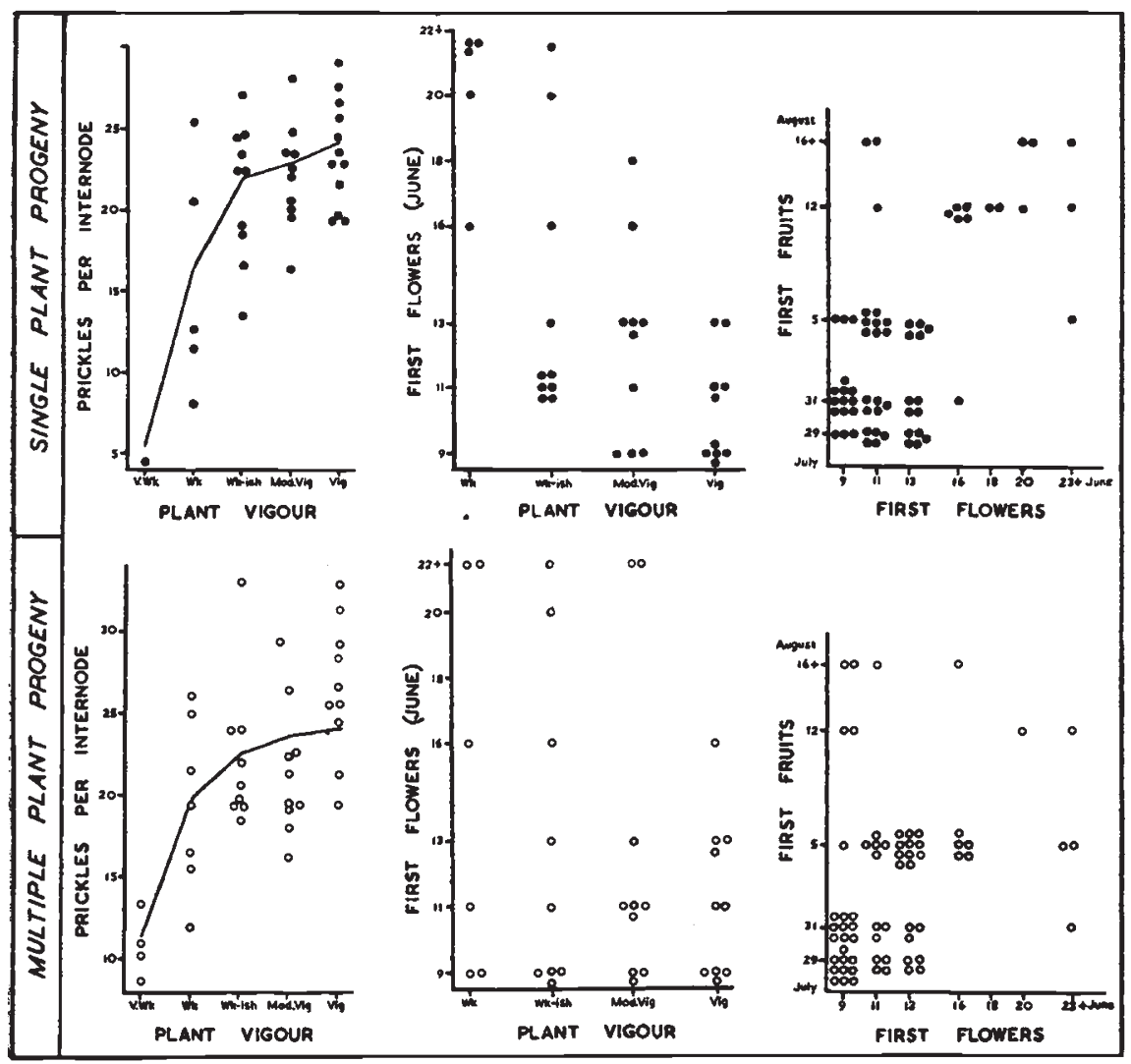

Fig. 2.-Correlations between quantitative characters in two families of Rubus nitidioides. Open circles represent Fam. 3I from several "open-pollinated " plants, and black circles Fam. 32, from one selected plant " self-pollinated".

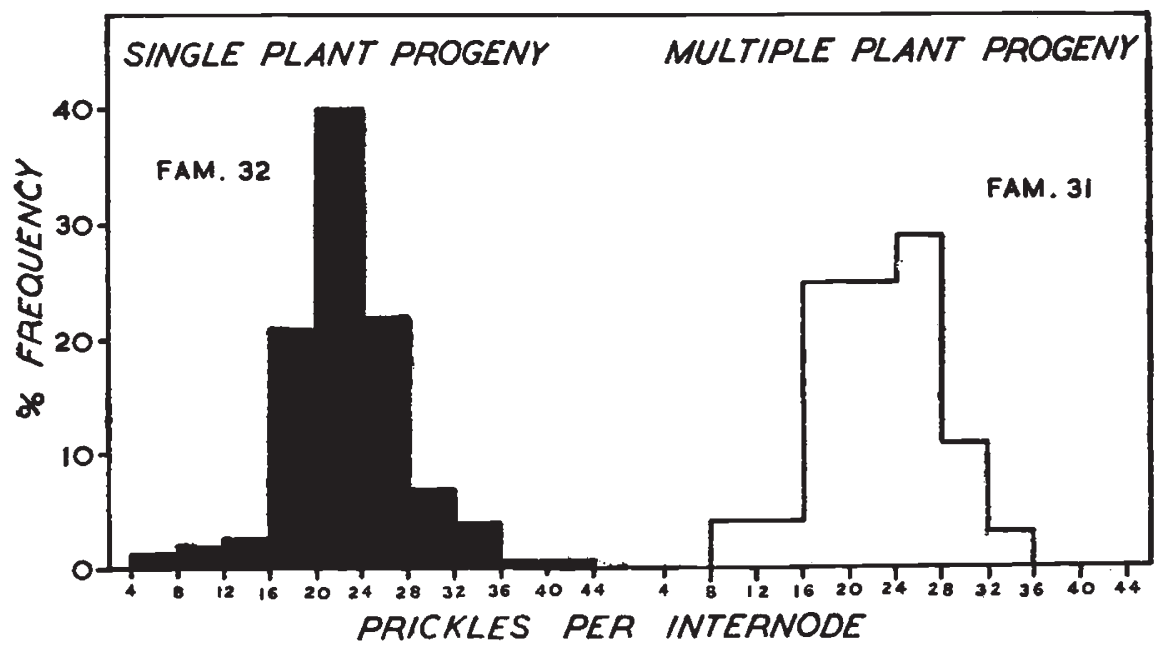

Fig. 3.-Frequency distributions of mean prickle number per internode, grouped in units of four, in two populations of Rubus nitidioides. Left histogram represents Fam. 32, from one plant "selfed"; right histogram represents Fam. $3^{1}$ from an "openpollinated" population. 
The percentage frequencies for times of appearance of first ripe fruits are modified by those plants in both families which were either too late in fruiting, or lacked flowers, or these were diseased and died off. Little difference can be detected in this character between the two families; they are remarkably alike (fig. I), except that 20 per cent. of Fam. 3 I failed to fruit, almost entirely on plants affected by disease.

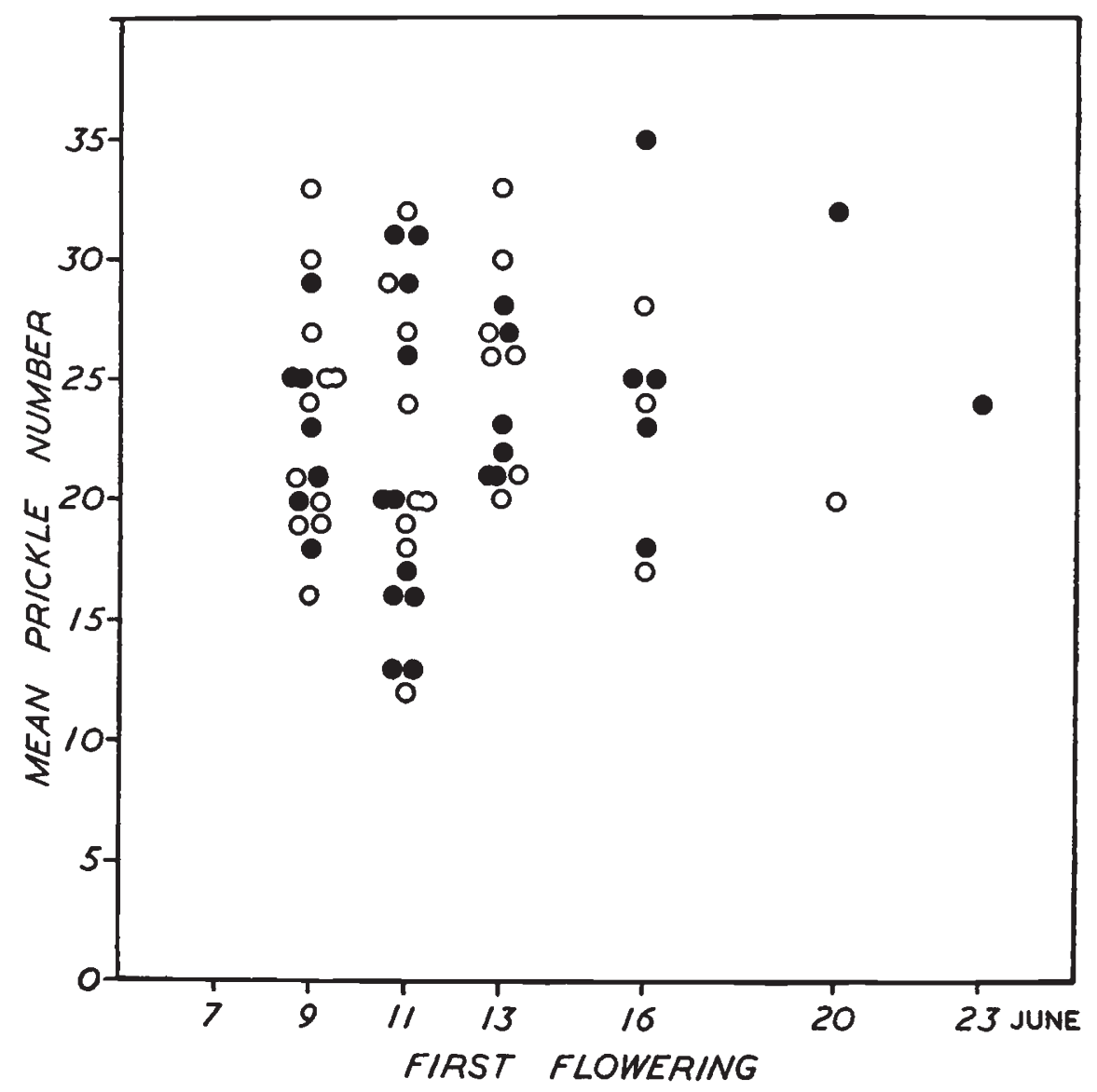

Frc. 4.-Scatter diagram to show range of variation with respect to prickle number per internode and to first flowering times within two populations of Rubus nitidioides. Fam. 3I (from open-pollinated parents) is represented by open circles; Fam. 32 (from one selfed plant) is represented by black circles.

Fig. 2 shows the correlation between first flowering and first fruiting, and indicates that for these characters it is surprisingly weak. Plants with earliest flowers do not necessarily produce the first ripe berries. Many environmental factors must come into play to effect fruiting. There is also moderate correlation between first flowering and general plant vigour. 


\section{VARIATION RANGES IN PURE AND MIXED APOMICTIC FAMILIES}

A test was made to compare the range of variation in both families. This helps to determine how far variation differences between families are due purely to variation within an apomict or, a possibility in Fam. 3I, to sexual segregation. Two quantitative characters, considered sufficiently unrelated, were used. These were prickle number and time of first flowering. Data were taken from thirty representative plants and plotted as scatter diagrams (fig. 4), following the method of Babcock and Stebbins (1938).

Distribution and concentration for both families is remarkably similar. Thus although slightly wider segregation of prickle number was discerned in Fam. 32 ( $c f$. fig. 3), there is no indication that it of the degree expected with sexual segregation. Similarly, the multiple progeny of Fam. 3I showed no wider variation range than that of the single progeny in Fam. 32. Thus although variation is detectable within different families of $R$. nitidioides according to their ancestry, it is extremely limited and is in the nature of subsexual auto-segregation.

\section{ORIGIN OF SEGREGATION}

The highest prickled plant, called $\mathrm{H}_{1}$, showed several associated quantitative features such as late flowering, comparative paucity of inflorescences and fruits, and its drupels often swelled without seed formation, i.e. by parthenocarpy. On the other hand, the next highest plant, $\mathrm{H}_{2}$, and the two plants with lowest prickles, called $\mathrm{L}_{1}$ and $\mathrm{L}_{2}$ respectively, were similar to others in both populations. It cannot therefore be ruled out that $\mathrm{H}_{1}$ results from recombination following true sexual union; nor is there any way of detecting true sexual plants among apomicts within the families. In the open-pollinated Fam. $3^{1}$ there is the possibility of their occurrence and recognition in chance outcrosses with other species. However, there were none, nor was any major gene segregating. A character such as anthocyanin would be extremely useful as a marker gene in these studies : on the basis of Vavilov's law of homologous variation, it may eventually be obtained as a mutant because it occurs in other Rubus species.

It is not necessary to attribute any of the quantitative variation to loss or gain of chromosomes, for Thomas (1940) showed that chromosome number is constant in $R$. nitidioides. Moreover, since no major differences were seen, monosomics such as found in variants of apomictic Erigeron annuum and Taraxacum (cf. Gustafsson, 1947) need not be suspected.

As between the families, 3 I was more variable in some characters, but both were remarkably similar for most such as time of first fruiting. On the whole, greatly restricted variation is present, well shown by the scatter diagrams of the variation ranges (fig. 4). Yet there is still 
sufficient subsexual variation to allow detection of differences according to the genetic history of each family.

Morphological variation in apomicts besides Rubus are known, e.g. in Parthenium argentatum (Rollins, 1945) and Taraxacum. In Parthenium variants occur not only with reduced chromosome number, shorter trichomes and pollen differences, unlike Rubus, but also among individuals showing no chromosomal changes ; these deviations within the apomicts have slower growth. Because environment was constant, Rollins attributed this latter variation to genetic differences within the same age-group. As rather small families were used, possibly a continuous variation as in $R$. nitidioides, rather than the assumed discontinuous differences, also occurred in Parthenium.

It may be asked whether a plant has greater chances of true sexual reproduction when selfed than when sibbed (i.e. sister-crossed) or outcrossed to other species. Gustafsson (1939) assessed available evidence in Rubus and found that the amount of sexual fusion is unrelated to parental relationships. Thus although some of the variation might be attributable to the pollen parent, probably this has not been of importance in influencing the variations of either Fam. 31 or 32. And only the seed-bearing plant, where crossing-over occurs, is of practical interest. One may conclude that because of difficulty in clonally propagating Merton Early, it may safely be raised from "selfed" seed of best plants without deterioration or immediate deviation in the stock, either from inbreeding depression or from subsexual segregation.

\section{CONSEQUENCES OF POLYGENIC VARIATION}

Mather (1949) has described the obscuring effect of non-heritable variation on the segregation of polygenes in sexual plants. Even though prickle number per internode was highly variable within plants, the effects based on mean values are quite clear (fig. 3). Non-heritable variation no doubt plays a large role in influencing the quantitative variation of apomicts like the progenies of Merton Early ; even greater within-plant variation might be expected when they are grown under unsuitable conditions to which they are unadapted (Haskell, r 953). Since groups of polygenes acting as effective factors are subject to mutation and recombination, one can predict that following quantitative selection, even subsexual apomicts will ultimately show correlated responses like those of sexual species, e.g. Drosophila (Mather and Harrison, r949) and various plants (Haskell, 195I). Thus from the current experiment on selection for high and low prickles we shall be able to see whether, for example, there is a gradual drop in fertility. Similarly, if as Crane (I94I) has suggested, $R$. nitidioides originates from hybridisation together with unreduced gametes, its heterozygosity is concealed by the resulting apomixis, yet auto-segregation is then facilitated (Gustafsson, 1947). Thus 
heterozygosity together with mutation potentially can produce considerable differentiation. Hence a study of quantitative characters in $R$. calvatus, an apomict without segregation according to Thomas ( 1940 ), would be of comparative interest.

\section{PRACTICAL BREEDING PROBLEMS}

In Merton Early there are no complications due to segregation of chromosome numbers or unreduced gametes; also there is only one morphological form. Hence at first glance there seems no direct disadvantage to the grower as to what seed he harvests, providing he rogues any sexual species-hybrids, easily recognisable among offspring of open-pollinated seed. Now there is reason to suspect that loganberry stocks have changed owing to very similar seedlings, resulting from self-sown seeds, being unwittingly selected. As such small segregations even in a more or less constant species-hybrid are eventually felt, selection of apomictic seed from vigorous early Merton Early plants with low prickles should eventually produce some recognisable advantageous mild selection. Such an advantage in an apomict should be utilised, however slight.

There was no inbreeding depression ; progenies from both " selfed " and mixed "selfed-sibbed" families had similar vigour. Whether the 5 per cent. true intra-specific sexual individuals, possible according to Thomas (1940), show inbreeding depression cannot immediately be determined. Even so, apomictic seedlings from selfings of the best plants will maintain the line's vigour. Lewis (unpublished) has found in raspberries that the first selfed generation is often more vigorous than the parents, owing to the elimination of viruses which are not seed transmitted; but later generations show the true extent of inbreeding depression. So far, however, virus diseases are not known in Merton Early so this complication will not arise. Hence reproduction by seed is satisfactory, little variation in vigour either way from the original clone being expected. At the same time, owing to auto-segregation, seed should be retained only from earliest and most vigorous plants free from disease.

In practical cultivation there may be advantages in having some discontinuity in a sample of seedlings brought about by auto-segregation, for under cultivation complete uniformity of crops is not altogether desirable. Thus Hanson et al. (I952) have found mixtures of apomictic strains of $P o a$ pratensis better yielding than single strains, especially when tall and dwarf types are mixed.

\section{SUMMARY}

I. Quantitative characters were studied in two pseudogamous subsexual families of Rubus nitidioides. One came from a single selected self-pollinated plant (Fam. 32) and the other from several openpollinated plants (Fam. 3I). Fam. 32 suffered no inbreeding depression following "selfing". 
2. Plant vigour histograms showed that Fam. 31, but not Fam. 32, might consist of several overlapping frequency distributions. Prickle frequency was normally distributed in Fam. 32, but Fam. $3^{\mathrm{I}}$ had no central peak, confirming that the former was a single, segregating

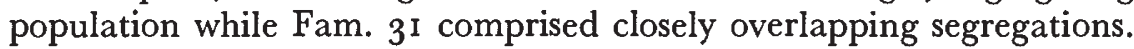

3. First flowering times and fruit maturities were highly uniform and similar in both families, but there was weak correlation for individual plants.

4. Variation ranges in both families were compared by plotting prickle numbers against flowering times. As both had similar distribution, there was no evidence of genuine and widespread sexual reproduction. Variation, although detectable, was extremely limited, attributable to auto-segregation rather than to true sexual segregation.

5. Prickle number might be,reduced by selection. Hence further study of selection in subsexual apomicts has theoretical and economic interest.

Acknowledgments.-Thanks are due to $\mathrm{Mr}$ A. G. Brown for useful advice and to Dr G. D. Darlington for guidance in the preparation of this manuscript.

\section{REFERENCES}

BABcock, E. B., AND stebbins, G. L. JR. 1938. The American species of Crepis. Carnegie Inst. Wash. Pub., 504, I-1 99.

CRANE, M. B. r940. Reproductive versatility in Rubus. I. Morphology and inheritance. F. Genet., 40 , sog-I I 8.

CRANe, M. B. I 94I. New blackberries. Gard. Illus., 63, 56r.

CRANE, M. B., AND THOMAS, P. T. I 939 . Segregation in asexual (apomictic) offspring in Rubus. Nature, Lond., I43, 684.

DARLington, G. D. I 932 . Recent Advances in Cytology. Ist ed. London : Churchill. DARLIngton, C. D. I 937 . Recent Advances in Cytology. 2nd ed. London: Churchill. DARROW, G. M., AND WALdo, G. F. 1933. Pseudogamy in blackberry crosses. $\mathcal{F}$. Hered., 24, 31 3-3 I 4 .

GUSTAFSSON, ^. I 939 . Differential polyploidy within the blackberries. Hereditas, $25,33-47$.

GUSTAFsSON, $\AA$. 1942. The origin and properties of the European blackberry flora. Hereditas, 28, 249-277.

gustafsson, $\AA$. 1943. The genesis of the European blackberry flora. Lund. Univ. Arks. N.F., 39, I-200.

gustafsson, ̊. I 947 . Apomixis in higher plants. Lund Univ. Arks. N.F., 43, I-370. haNSON, A. A., GARBER, R. J., AND MYers, W. M. I 952 . Yields of individual and combined apomictic strains of Kentucky bluegrass (Poa pratensis L.). Agron. 7., 44, 125-1 28.

HASKELL, G. I95I. Studies of the correlated responses in plants to selection for polygenic characters. Ph.D. Thesis in the University of London.

haskeld, G. 1953. Heterosis and adaptability. Proc. I3 Int. Hort. Congr., I, 365-374.

mather, K. I949. Biometrical Genetics. London : Methuen \& Co. Ltd.

MATHER, K., AND haRRison, B. J. I 949 . The manifold effect of selection. Heredity, $3, \mathrm{I}-52, \mathrm{I} 3 \mathrm{I}-\mathrm{I} 62$.

ROLLINS, R. C. I945. Evidence for genetic variation among apomictically produced plants of several $F_{1}$ progenies of guayule (Parthenium argentatum) and mariola (P. incanum). Amer. F. Bot., 32, 554-56o.

THomas, P. T. 1940. Reproductive versatility in Rubus. II. The chromosomes and development. F. Genet., $4^{\circ}$, I I 9 - 128. 